\title{
High-Nuclearity Manganese and Iron Complexes with the Anionic Ligand Methyl Salicylimidate
}

\author{
Meenal D. Godbole, ${ }^{\dagger}$ Olivier Roubeau, ${ }^{\ddagger}$ Allison M. Mills,,$\S$ Huub Kooijman,,$\S$ Anthony L. Spek,,$\S$ and \\ Elisabeth Bouwman ${ }^{*}, \dagger$ \\ Leiden Institute of Chemistry, Gorlaeus Laboratories, Leiden University, P.O. Box 9502, 2300 RA \\ Leiden, The Netherlands, Centre de Recherche Paul Pascal CNRS UPR-8641, 115 avenue du dr. \\ Schweitzer, 33600 PESSAC, France, and Bijvoet Center for Biomolecular Research, Crystal and \\ Structural Chemistry, Utrecht University, The Netherlands
}

Received March 29, 2006

\begin{abstract}
The three novel clusters $\left[\mathrm{Mn}_{6} \mathrm{O}_{4}(\mathrm{OMe})_{2}(\mathrm{OAc})_{4}(\mathrm{Mesalim})_{4}\right]$ (3), $\left[\mathrm{Mn}_{8} \mathrm{O}_{2}(\mathrm{OH})_{2}(\mathrm{OMe})_{12}(\mathrm{OAc})_{2}(\mathrm{Mesalim})_{4}\right]$ (4), and $\left[\mathrm{Fe}_{10} \mathrm{O}_{4}(\mathrm{OMe})_{14} \mathrm{Cl}_{2}(\text { Mesalim) })_{6}\right](5)$ have been synthesized from a simple bidentate ligand HMesalim (HMesalim = methyl salicylimidate). Starting from the mononuclear complex $\left[\mathrm{Mn}(\text { Mesalim })_{2}(\mathrm{OAc})(\mathrm{MeOH})\right] \cdot \mathrm{MeOH}(1)$, either the hexanuclear complex $\mathbf{3}$ or the octanuclear complex $\mathbf{4}$ is obtained after recrystallization, depending upon the reaction conditions and solvents used. Similarly, starting from the purple-colored mononuclear complex $\left[\mathrm{Fe}(\mathrm{Mesalim})_{2} \mathrm{Cl}\right]$ (2), the orange-colored decanuclear iron(III) cluster $\mathbf{5}$ has been obtained upon recrystallization from methanol. Complex 3 , which could also be prepared directly from manganese acetate and the ligand, has a face-sharing double-cubane $\left[\mathrm{Mn}_{6} \mathrm{O}_{6}\right]$ core, unique in transition metal chemistry. Compounds 4 and 5 are composed of $\left[\mathrm{M}_{3} \mathrm{O}_{4}\right]$ partial cubanes. All complexes belong to a class of oxo-bridged cubic close-packed molecular clusters resembling the metal oxide/hydroxide ores. Complex 4 exhibits intramolecular ferromagnetic interactions, as evidenced from dc magnetic susceptibility studies $(1.8-300 \mathrm{~K})$, resulting in a high-spin ground state, probably with $S_{T}=8$. Complex 4 displays single molecule magnet behavior as indicated by frequency and temperature dependences of its ac susceptibility. An Arrhenius plot gave relatively large experimental activation energy of $36.0 \mathrm{~K}$. The magnetic properties of complexes $\mathbf{3}$ and $\mathbf{5}$ are dominated by antiferromagnetic interactions leading to zero-spin ground states.
\end{abstract}

\section{Introduction}

The design and synthesis of novel polynuclear manganese and iron clusters with primarily oxygen and nitrogen coordination are active areas of current chemical research. Clusters comprising manganese or iron ions are present in several metalloenzymes and metalloproteins ranging from the protein ferritin, ${ }^{1,2}$ responsible for iron storage, to the water oxidizing complex of photosystem II of bacterial photosynthesis. ${ }^{3,4}$ In molecular magnetism, manganese and iron ion assemblies with high nuclearities and appropriate topologies

\footnotetext{
* To whom correspondence should be addressed. E-mail: bouwman@chem.leidenuniv.nl.

$\dagger$ Leiden University.

Centre de Recherche Paul Pascal.

$\S$ Utrecht University.

(1) Kurtz, D. M. Chem. Rev. 1990, 90, 585-606.

(2) Lippard, S. J. Angew. Chem., Int. Ed. Engl. 1988, 27, 344-361.

(3) Dismukes, G. C. In Bioinorganic Catalysis; Reedijk, J., Ed.; Marcel Dekker: New York, 1993; p 317.

(4) Mukhopadhyay, S.; Mandal, S. K.; Bhaduri, S.; Armstrong, W. H. Chem. Rev. 2004, 104, 3981-4026.
}

10.1021/ic0605322 CCC: $\$ 33.50$ (C) 2006 American Chemical Society Published on Web 07/29/2006 can sometimes possess large ground spin $(S)$ values and can function as single-molecule magnets (SMMs). ${ }^{5-8}$ Such an SMM displays slow relaxation of its magnetization and functions as a magnet below its so-called blocking temperature $\left(T_{\mathrm{B}}\right){ }^{9-11}$ While at low temperatures quantum tunneling becomes the dominant relaxation path for the magnetization, a thermally activated regime dominated mainly by the spin ground state $\left(S_{\mathrm{T}}\right)$ and the uniaxial anisotropy $(D)$ of the molecule is observed at higher temperatures. In this regime,

(5) Murugesu, M.; Habrych, M.; Wernsdorfer, W.; Abboud, K. A.; Christou, G. J. Am. Chem. Soc. 2004, 126, 4766-4767.

(6) Christou, G.; Gatteschi, D.; Hendrickson, D. N.; Sessoli, R. MRS Bull. 2000, 25, 66-71.

(7) Gatteschi, D.; Sessoli, R. J. Magn. Magn. Mater. 2004, 272-76, 1030-1036.

(8) Tasiopoulos, A. J.; Vinslava, A.; Wernsdorfer, W.; Abboud, K. A.; Christou, G. Angew. Chem., Int. Ed. 2004, 43, 2117-2121.

(9) Gatteschi, D.; Sessoli, R. Angew. Chem., Int. Ed. 2003, 42, 268-297.

(10) Ritter, S. K. Chem. Eng. News 2004, 82, 29-32.

(11) Sessoli, R.; Tsai, H. L.; Schake, A. R.; Wang, S. Y.; Vincent, J. B.; Folting, K.; Gatteschi, D.; Christou, G.; Hendrickson, D. N. J. Am. Chem. Soc. 1993, 115, 1804-1816.

Inorganic Chemistry, Vol. 45, No. 17, 20066713 


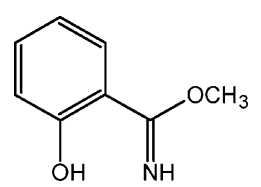

Figure 1. The ligand methyl salicylimidate.

the theoretical energy barrier $(\Delta)$ is equal to $|D| S_{\mathrm{T}}^{2}$ or $|D|$ $\left(S_{\mathrm{T}}{ }^{2}-1 / 4\right)$ for integer and half-integer $S_{\mathrm{T}}$, respectively. Thus, it is important to find molecules exhibiting large spins and/ or large $D$ values. $\mathrm{Mn}$ (III) ions, having a $\mathrm{d}^{4}$ ground state and negative magnetic anisotropy, are perfect candidates for development of molecular magnetic materials. The high-spin iron(III) ion ( $\left.\mathrm{d}^{5}\right)$, having an $S=5 / 2$ ground state, is also a potential building block to achieve large spin in the ground state, but due to its ${ }^{6} \mathrm{~S}$ nature, it generally forms antiferromagnetically coupled clusters. ${ }^{12,13}$ However, certain $\mathrm{Fe}_{x}$ topologies have resulted in large ground spin states due to the occurrence of the spin frustration effects, showing slow magnetic relaxation and magnetic hysteresis. ${ }^{14,15} \mathrm{~A}$ major obstruction to the practical application of these nanomagnets is the low blocking temperatures up to which the molecule behaves as a nanomagnet. Although many efforts have been made to increase $\Delta$ and $T_{\mathrm{B}}$, the first family of SMMs, $\left[\mathrm{Mn}_{12} \mathrm{O}_{12}(\mathrm{OR})_{12}\left(\mathrm{H}_{2} \mathrm{O}\right)_{4}\right]$, still displays the highest blocking temperatures of all the complexes studied so far. ${ }^{11,16,17}$ A major goal in the development of new nanomagnets is to develop ligands that give rise to novel clusters in order to rationalize the geometry, nuclearity, and topologies of $\mathrm{Mn}$ and Fe clusters. Through the development of new varieties of SMMs high blocking temperatures could be achieved, which would permit their use as in actual applications.

During the studies on new epoxidation catalysts based on manganese complexes, the ligand methyl salicylimidate (HMesalim) (Figure 1) has proven to be a useful synthetic intermediate. The coordination chemistry of the ligand appears to be very rich, and recently, crystal structures of three manganese complexes, as well as their catalase activities, have been published. ${ }^{18,19}$ In this manuscript, the syntheses, X-ray crystal structures, and detailed magnetic properties of three novel high nuclearity manganese and iron complexes, $\left[\mathrm{Mn}_{6} \mathrm{O}_{4}(\mathrm{OMe})_{2}(\mathrm{OAc})_{4}(\mathrm{Mesalim})_{4}\right](\mathbf{3}),\left[\mathrm{Mn}_{8} \mathrm{O}_{2-}\right.$ $\left.(\mathrm{OH})_{2}(\mathrm{OMe})_{12}(\mathrm{OAc})_{2}(\mathrm{Mesalim})_{4}\right](4)$, and $\left[\mathrm{Fe}_{10} \mathrm{O}_{4}(\mathrm{OMe})_{14^{-}}\right.$ $\mathrm{Cl}_{2}$ (Mesalim) $)_{6}$ (5) are reported. The structure and magnetism of compound $\mathbf{4}$ have been communicated previously. ${ }^{20}$

(12) Canada-Vilalta, C.; O'Brien, T. A.; Pink, M.; Davidson, E. R.; Christou, G. Inorg. Chem. 2003, 42, 7819-7829.

(13) Glaser, T.; Lügger, T.; Hoffmann, R. D. Eur. J. Inorg. Chem. 2004, $2356-2362$

(14) Barra, A. L.; Brunel, L. C.; Gatteschi, D.; Pardi, L.; Sessoli, R. Acc. Chem. Res. 1998, 31, 460-466.

(15) Jones, L. F.; Brechin, E. K.; Collison, D.; Raftery, J.; Teat, S. J. Inorg. Chem. 2003, 42, 6971-6973.

(16) Sessoli, R.; Gatteschi, D.; Caneschi, A.; Novak, M. A. Nature 1993 $365,141-143$

(17) Caneschi, A.; Gatteschi, D.; Sessoli, R.; Barra, A. L.; Brunel, L. C.; Guillot, M. J. Am. Chem. Soc. 1991, 113, 5873-5874.

(18) Godbole, M. D.; Grigiotti, E.; Zanello, P.; Mills, A. M.; Spek, A. L.; Bouwman, E. Inorg. Chim. Acta 2005, 358, 233-238.

(19) Godbole, M. D.; Kloskowski, M.; Hage, R.; Rompel, A.; Mills, A. M.; Spek, A. L.; Bouwman, E. Eur. J. Inorg. Chem. 2005, 305-313.

\section{Experimental Section}

Physical Measurements. UV/vis-NIR measurements were performed on a Perkin-Elmer Lambda 900 UV/vis - NIR spectrometer. IR spectra were recorded on a Perkin-Elmer FT-IR Paragon 1000 spectrometer. Elemental analyses were performed with a Perkin-Elmer series II CHNS/O analyzer 2400. Magnetic measurements were done with a Quantum Design MPMS-XL squid magnetometer on slightly powdered polycrystalline samples. Corrections for the sample holder (empirically determined) and intrinsic diamagnetism (Pascal constants) of the samples were applied. All solvents were of analytical grade and used without further purification unless stated otherwise.

Syntheses. The ligand HMesalim was synthesized according to the reported procedure. ${ }^{21-23}$ Synthesis of the complex [Mn$\left.(\text { Mesalim })_{2}(\mathrm{OAc})(\mathrm{MeOH})\right] \cdot \mathrm{MeOH}(\mathbf{1})$ has been described elsewhere. ${ }^{19}$

[Fe(Mesalim) $)_{2} \mathbf{C l}$ (2). To a solution of $0.1 \mathrm{~g}(0.662 \mathrm{mmol})$ of HMesalim in $5 \mathrm{~mL}$ of $\mathrm{CH}_{3} \mathrm{CN} / \mathrm{MeOH}(50: 50 \mathrm{v} / \mathrm{v}) 0.054 \mathrm{~g}(0.332$ mmol) of solid $\mathrm{FeCl}_{3}$ was added. The resulting purple-red solution was stirred for $30 \mathrm{~min}$. The solution was filtered, and crystalline product was obtained by slow diffusion of a mixture of hexane/ $\mathrm{Et}_{2} \mathrm{O}(1: 1, \mathrm{v} / \mathrm{v})$ into the reaction mixture. Yield of crude product: 68\% (0.08 g); IR (diamond): 3308(m), 3023(s), 1614(s), 1587(m), 1538(vs), 1452(m), 1435(m), 1385(s), 1329(s), 1261(s), 1204(s), 1157(m), 1099(s), 1033(s), 960(s), 864(s), 788(m), 750(vs), 665(m), 629(m), 563(s), 528(s), 481(s), 435(s) $\mathrm{cm}^{-1}$. Anal. Calcd (\%) for $\mathrm{C}_{16} \mathrm{H}_{16} \mathrm{ClFeN}_{2} \mathrm{O}_{4}$ (fw = 391.61): C, 49.07; H, 4.12; $\mathrm{N}$, 7.15. Found: $\mathrm{C}, 49.0 ; \mathrm{H}, 4.5 ; \mathrm{N}, 7.3$.

$\left[\mathrm{Mn}_{6} \mathrm{O}_{4}(\mathrm{OMe})_{2}(\mathrm{OAc})_{4}(\mathrm{Mesalim})_{4}\right]$ (3). To a solution of $0.2 \mathrm{~g}$ $(1.32 \mathrm{mmol}$ ) of HMesalim in $5 \mathrm{~mL}$ of $\mathrm{MeOH}$ a solution of 0.486 $\mathrm{g}(1.98 \mathrm{mmol})$ of $\mathrm{Mn}$ (II) acetate in $5 \mathrm{~mL}$ of $\mathrm{MeOH}$ was added. The resulting brown solution was stirred for $30 \mathrm{~min}$ at $50{ }^{\circ} \mathrm{C}$ to ensure complete dissolution and the formation of a homogeneous solution. The solution was filtered, and crystals suitable for X-ray analysis were obtained by slow diffusion of a hexane/Et ${ }_{2} \mathrm{O}(1: 1$ $\mathrm{v} / \mathrm{v})$ mixture into the reaction mixture. Yield of crude product: $23 \%$ $(0.1 \mathrm{~g})$; The complex 3 could also be obtained by slow diffusion of $\mathrm{Et}_{2} \mathrm{O}$ into a solution of $\mathbf{1}$ in $\mathrm{MeOH}$ at room temperature. However, complex $\mathbf{3}$ obtained with this route was less pure, as observed from the elemental analyses. IR (diamond): 3268(m), 1606(s), 1588(s), 1455(s), 1399(s), 1214(m), 1088(vs), 959(m), 868(m), 758(s), 618(s), 523(s), 427(s) $\mathrm{cm}^{-1}$. Anal. Calcd (\%) for $\mathrm{C}_{42} \mathrm{H}_{50^{-}}$ $\mathrm{Mn}_{6} \mathrm{~N}_{4} \mathrm{O}_{22}(\mathrm{fw}=1292.50): \mathrm{C}, 39.71 ; \mathrm{H}, 4.26 ; \mathrm{N}, 4.21$. Found: C, $39.0 ; \mathrm{H}, 3.9 ; \mathrm{N}, 4.3$.

$\left[\mathrm{Mn}_{8} \mathrm{O}_{2}(\mathrm{OH})_{2}(\mathrm{OMe})_{12}(\mathrm{OAc})_{2}(\text { Mesalim })_{4}\right]$ (4). The complex $\left[\mathrm{Mn}(\mathrm{Mesalim})_{2}(\mathrm{OAc})(\mathrm{MeOH})\right] \cdot \mathrm{MeOH}(0.5 \mathrm{~g})$ was dissolved in $\mathrm{MeOH}(250 \mathrm{~mL})$, and the solution was filtered. The solution was kept in a $250 \mathrm{~mL}$ conical flask with a stopper and allowed to stand for 2-3 months. Brown crystals suitable for X-ray analysis were obtained in a very low yield. The brown crystals were the sole product isolated from the solution. Despite the long reaction time and low yields, the complex has been reproduced several times. Yield of crude product: 5\% (10 mg); IR (diamond): 2907(m), 2809(s), 1616(s), 1550(s), 1544(s), 1452(m), 1397(vs), 1336(m), 1266(m), 1211(s), 1158(s), 1139(s), 1063(s) 1035(m), 866(s), 756(s), 866(s), 635(s), 550(m), $\mathrm{cm}^{-1}$. Anal. Calcd (\%) for $\mathrm{C}_{48} \mathrm{H}_{76^{-}}$

(20) Godbole, M. D.; Roubeau, O.; Clérac, R.; Kooijman, H.; Spek, A. L.; Bouwman, E. Chem. Commun. 2005, 3715-3717.

(21) Stoss, P. Chem. Ber. 1978, 111, 314-319.

(22) Vinkler, P.; Thimm, K.; Vob, J. Liebigs Ann. Chem. 1976, 1976 , 2083-2093.

(23) Black, D. S. C.; Wade, M. J. Aust. J. Chem. 1972, 25, 1797-1810.

6714 Inorganic Chemistry, Vol. 45, No. 17, 2006 
Table 1. Crystal Data for Complexes $\mathbf{3}, \mathbf{4}$, and $\mathbf{5}$

\begin{tabular}{|c|c|c|c|}
\hline & 3 & 4 & 5 \\
\hline formula $^{a}$ & $\mathrm{C}_{42} \mathrm{H}_{50} \mathrm{Mn}_{6} \mathrm{~N}_{4} \mathrm{O}_{22}$ & $\mathrm{C}_{48} \mathrm{H}_{76} \mathrm{Mn}_{8} \mathrm{~N}_{4} \mathrm{O}_{28}$ & $\mathrm{C}_{62} \mathrm{H}_{90} \mathrm{Cl}_{2} \mathrm{Fe}_{10} \mathrm{~N}_{6} \mathrm{O}_{30}$ \\
\hline $\mathrm{fw}, \mathrm{g} / \mathrm{mol}^{a}$ & 1292.50 & 1596.65 & 2028.80 \\
\hline cryst syst & triclinic & monoclinic & triclinic \\
\hline space group & $P \overline{1}$ (No. 2) & $P 21 / c$ (No. 14) & $P \overline{1}$ (No. 2) \\
\hline$a, \AA$ & $10.3718(2)$ & $9.753(3)$ & $10.7152(3)$ \\
\hline$b, \AA$ & $11.8762(3)$ & $27.559(6)$ & $12.7086(3)$ \\
\hline$c, \AA$ & $13.4373(3)$ & $25.860(8)$ & $16.3521(6)$ \\
\hline$\alpha, \operatorname{deg}$ & $78.6455(8)$ & & $110.1462(11)$ \\
\hline$\beta, \operatorname{deg}$ & $79.7779(8)$ & $115.621(13)$ & $101.8144(11)$ \\
\hline$\gamma, \operatorname{deg}$ & $79.5352(9)$ & & $92.868(2)$ \\
\hline$V, \AA^{3}$ & $1578.46(6)$ & $6267(3)$ & $2028.54(11)$ \\
\hline Z & 1 & 4 & 1 \\
\hline$\rho_{\text {calc }}, \mathrm{g} / \mathrm{cm}^{3} a$ & 1.360 & 1.692 & 1.661 \\
\hline$\mu, \mathrm{mm}^{-1 a}$ & 1.231 & 1.643 & 1.879 \\
\hline$[T, \mathrm{~K}]$ & {$[150]$} & {$[150]$} & {$[150]$} \\
\hline transmisson range & $0.841-0.979$ & $0.787-0.880$ & $0.822-0.948$ \\
\hline total reflns & 24397 & 95838 & 23629 \\
\hline unique reflns & 6182 & 11344 & 7128 \\
\hline params & 339 & 811 & 496 \\
\hline wR2 & 0.0971 & 0.1582 & 0.1155 \\
\hline $\mathrm{R} 1[I>2 \sigma(I)]$ & 0.0395 (4579 reflns) & 0.0816 (5644 reflns) & 0.0471 (4927 reflns) \\
\hline$S$ & 1.05 & 1.06 & 1.05 \\
\hline
\end{tabular}

${ }^{a}$ Where relevant, without disordered solvent contribution.

$\mathrm{Mn}_{8} \mathrm{~N}_{4} \mathrm{O}_{28}(\mathrm{fw}=1596.65): \mathrm{C}, 36.1 ; \mathrm{H}, 4.8 ; \mathrm{N}, 3.5$. Found: $\mathrm{C}$, 35.9; H, 4.6; N, 3.5.

$\left[\mathrm{Fe}_{10} \mathbf{O}_{\mathbf{4}}(\mathbf{O M e})_{14} \mathbf{C l}_{\mathbf{2}}(\text { Mesalim) })_{6}\right]$ (5). Complex 2 (20 mg) was dissolved in $10 \mathrm{~mL}$ of $\mathrm{MeOH}$, and the covered solution was left to stand for 1-2 months. The purple solution turned orange over time and gave small orange crystals suitable for X-ray analysis. Yield of crude product: $70 \%$ (7 mg); IR (diamond) 3302(m), 2915(m), 2814(m), 1618(s), 1546(w), 1470(m), 1449(s), 1389(s), 1326(s), 1262(s), 1202(s), 1153(s), 1096(m), 1048(vs), 869(m), 785(w), 751(s), 668(m), 599(s) 457(m), 460(m), 394(m) cm $\mathrm{c}^{-1}$. Anal. Calcd (\%) for $\mathrm{C}_{62} \mathrm{H}_{90} \mathrm{Cl}_{2} \mathrm{Fe}_{10} \mathrm{~N}_{6} \mathrm{O}_{30} \cdot 4 \mathrm{H}_{2} \mathrm{O}$ (fw $\left.=2100.72\right)$ : C, 35.45; H, 4.70; N, 4.00. Found: C, 35.6; H, 4.9; N, 3.9.

X-ray Crystallographic Study. Data on measurement and structure determination for $\mathbf{3}, \mathbf{4}$, and $\mathbf{5}$ are presented in Table 1 . The structure of $\mathbf{4}$ has been communicated; ${ }^{20}$ however, for comparison the most relevant data are included in this manuscript. Intensity data for $\mathbf{3 , 4}$, and $\mathbf{5}$ were collected at $150 \mathrm{~K}$ on a Nonius Kappa CCD diffractometer with rotating anode (Mo $\mathrm{K}_{\alpha}, \lambda=$ $0.71073 \AA$ ). A multiscan absorption correction was applied to each data set using PLATON/MULABS. ${ }^{24}$ The structures were solved by direct methods using SHELXS97 and refined on $F^{2}$ using SHELXL97. ${ }^{25}$ Crystal structures 3 and $\mathbf{5}$ contain voids $\left(453.9 \AA^{3 /}\right.$ unit cell for 3; $106.9 \AA^{3} /$ unit cell for 5) filled with disordered methanol solvent molecules. Their contribution to the structure factors was ascertained using PLATON/SQUEEZE (106 e/unit cell for 3; 15 e/unit cell for 5). ${ }^{24}$ All non-hydrogen atoms were refined with anisotropic displacement parameters. The imine hydrogen atoms were positively identified in a difference Fourier map. All hydrogen atoms were constrained to idealized geometries and allowed to ride on their carrier atoms with an isotropic displacement parameter related to the equivalent displacement parameter of their carrier atoms. The $\mathrm{H}$ atom of the $\mathrm{H}$-bonded systems $\mathrm{O} 3 \cdots \mathrm{O} 112$ and $\mathrm{O} 4 \cdots \mathrm{O} 114$ in complex $\mathbf{4}$ has been arbitrarily assigned to the $\mu_{3}-\mathrm{O}$ atom rather than the $\mu-\mathrm{OCH}_{3}$ atom. Structure validation and molecular graphics preparation were performed with the PLATON package. ${ }^{24}$

(24) Spek, A. L. PLATON; Utrecht University: Utrecht, The Netherlands, 2003.

(25) Sheldrick, G. M. SHELXS-97 and SHELXL-97; University of Göttingen: Göttingen, Germany, 1997.

\section{Results and Discussion}

Synthetic Aspects. The various polynuclear clusters described in this manuscript were mainly obtained by recrystallization of mononuclear complexes under a variety of conditions. The mononuclear complexes were obtained from straightforward synthetic procedures. The reaction of HMesalim with manganese(II) acetate in a 2:1 ratio in a methanol/ether mixture yields the mononuclear complex $\mathbf{1}$, the crystal structure of which has been described earlier. ${ }^{19}$ In a similar way, the reaction of HMesalim with iron(III) chloride in a 2:1 ratio in a THF/methanol mixture yields the purple complex 2, the composition of which has been confirmed by elemental analysis and IR spectroscopy. The IR of complex 2 strongly resembles that of the related manganese complex $\left[\mathrm{Mn}(\text { Mesalim })_{2} \mathrm{Cl}\right]$, indicating a similar square-pyramidal geometry for the iron(III) ion with two Mesalim ligands coordinating in the equatorial plane and the chloride ion bound in the axial position. ${ }^{18}$

Recrystallization of $\mathbf{1}$ resulted in the formation of the two novel clusters 3 and $\mathbf{4}$. Complex $\mathbf{1}$, when recrystallized from a bilayer system of methanol/hexane+diethyl ether $(1: 1 \mathrm{v} / \mathrm{v})$, gives brown crystals of complex $\mathbf{3}$, which thus may have been formed by hydrolysis as summarized in eq 1. Complex 4 was obtained after long standing of a dilute methanol solution of $\mathbf{1}$, following a reaction as given by eq 2 .

$$
\begin{array}{r}
6\left[\mathrm{Mn}(\text { Mesalim })_{2}(\mathrm{MeOH})(\mathrm{OAc})\right]+4 \mathrm{H}_{2} \mathrm{O} \rightarrow \\
{\left[\mathrm{Mn}_{6} \mathrm{O}_{4}(\mathrm{OMe})_{2}(\mathrm{OAc})_{4}(\mathrm{Mesalim})_{4}\right]+} \\
8 \mathrm{HMesalim}+2 \mathrm{HOAc}+4 \mathrm{MeOH} \\
8\left[\mathrm{Mn}(\mathrm{Mesalim})_{2}(\mathrm{MeOH})(\mathrm{OAc})\right]+4 \mathrm{H}_{2} \mathrm{O}+4 \mathrm{MeOH} \rightarrow \\
{\left[\mathrm{Mn}_{8} \mathrm{O}_{2}(\mathrm{OH})_{2}(\mathrm{OMe})_{12}(\mathrm{OAc})_{2}(\text { Mesalim })_{4}\right]+} \\
12 \mathrm{HMesalim}+6 \mathrm{HOAc}
\end{array}
$$

Similarly, slow evaporation of a methanolic solution of the complex 2 resulted in the formation of the decanuclear 
cluster $\mathbf{5}$. The overall reaction occurring in solution can be summarized as given in eq 3 .

$$
\begin{aligned}
& 10\left[\mathrm{Fe}(\text { Mesalim })_{2} \mathrm{Cl}\right]+4 \mathrm{H}_{2} \mathrm{O}+14 \mathrm{MeOH} \rightarrow \\
& \quad\left[\mathrm{Fe}_{10} \mathrm{O}_{4}(\mathrm{OMe})_{14} \mathrm{Cl}_{2}(\text { Mesalim })_{6}\right]+8 \mathrm{HCl}+14 \mathrm{HMesalim}
\end{aligned}
$$

Reaction of metal salts with a ligand in appropriate ratios with use of sodium methoxide as a source of methoxide ions are commonly used methods for the synthesis of oxo/ methoxo-bridged, polynuclear manganese or iron complexes. These methods proved unsuccessful for the direct synthesis of complexes $\mathbf{4}$ and $\mathbf{5}$ in the present work. Complex $\mathbf{3}$ could, however, be synthesized directly in very good purity and yield by the reaction of HMesalim with manganese(II) acetate in a 2:3 ratio (eq 4 ).

$$
\begin{aligned}
& 6 \mathrm{Mn}(\mathrm{OAc})_{2} \cdot 4 \mathrm{H}_{2} \mathrm{O}+4 \mathrm{HMesalim}+2 \mathrm{MeOH}+{ }^{3} / \mathrm{O}_{2} \rightarrow \\
& \quad\left[\mathrm{Mn}_{6} \mathrm{O}_{4}(\mathrm{OMe})_{2}(\mathrm{OAc})_{4}(\text { Mesalim })_{4}\right]+8 \mathrm{HOAc}+23 \mathrm{H}_{2} \mathrm{O}
\end{aligned}
$$

It is possible that the extra oxidizing equivalents necessary for the oxidation of the $\mathrm{Mn}(\mathrm{II})$ ions to $\mathrm{Mn}(\mathrm{III})$ ions originate from atmospheric dioxygen or from oxidation products of solvent or ligand groups.

Unlike complex 3, complex 4 could not be synthesized directly by reaction of the metal and ligand with the use of sodium methoxide. Instead, IR spectra of the crystalline products obtained under these conditions showed the characteristic vibrations for both the complexes $\mathbf{3}$ and $\mathbf{4}$, suggesting that a mixture of the two complexes had formed.

The formation of manganese clusters from their mononuclear five- or six-coordinate complexes with other anions, such as chloride or bromide, has been demonstrated previously. ${ }^{26} \mathrm{By}$ controlling the solvents used for recrystallization of $\mathbf{1}$, the two different clusters from the same reaction mixture have been isolated in pure and crystalline form. However, recrystallization of the other mononuclear and dinuclear manganese complexes of the ligand HMesalim, [Mn$\left.(\text { Mesalim })_{2} \mathrm{Cl}\right]^{18}$ and $\left.\left[\mathrm{Mn}_{2}(\text { Etsalim })_{4}(\text { HEtsalim })_{2}\right]\left(\mathrm{ClO}_{4}\right)_{2}\right]^{19}$ $($ HEtsalim $=$ ethyl salicylimidate), did not yield any polynuclear species, even after several months, as confirmed with ESI-MS analysis of the solutions. Despite the low yields and longer times necessary for the crystallization, the complexes $\mathbf{3}, \mathbf{4}$ and $\mathbf{5}$ can be readily reproduced.

Description of the Crystal Structures. ORTEP representations of the molecular structures of $\mathbf{3}, \mathbf{4}$, and $\mathbf{5}$ are shown in Figures 2-4. PLUTON projections of the cores of the molecules are compared in Figure 5. Structural data and details of the data collection and refinement are summarized in Table 1. Selected bond distances are summarized in Tables 2-4 and hydrogen bond interactions are given in Table 5 .

A molecule of $\mathbf{3}$ can be regarded as a face-sharing doublecubane cluster with an $\left[\mathrm{Mn}_{6} \mathrm{O}_{6}\right]$ core. It consists of six $\mathrm{Mn}$ (III) cations, two $\mu_{4}-\mathrm{O}^{2-}$ anions, two $\mu_{3}-\mathrm{O}^{2-}$ anions, two $\mu_{3}-$ $\mathrm{OMe}^{-}$anions, four $\mathrm{OAc}^{-}$anions, and four terminal anionic

(26) Aromí, G.; Knapp, M. J.; Claude, J. P.; Huffman, J. C.; Hendrickson, D. N.; Christou, G. J. Am. Chem. Soc. 1999, 121, 5489-5499.

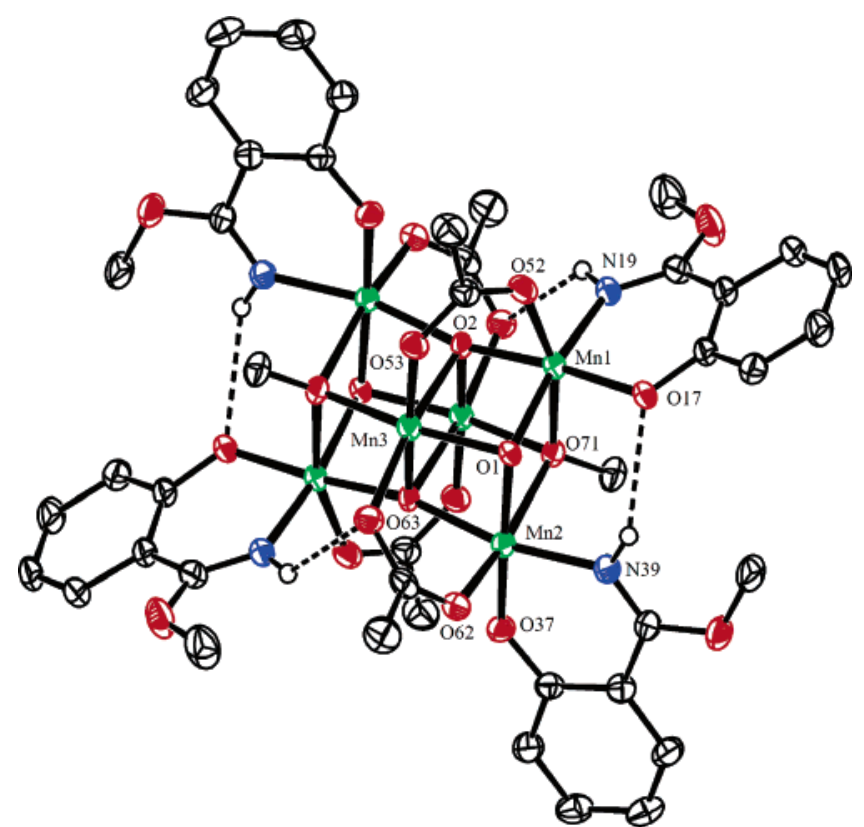

Figure 2. ORTEP representation of the molecular structure of $\mathbf{3}$ at $50 \%$ probability. Hydrogen atoms not involved in hydrogen bonding are omitted for clarity.

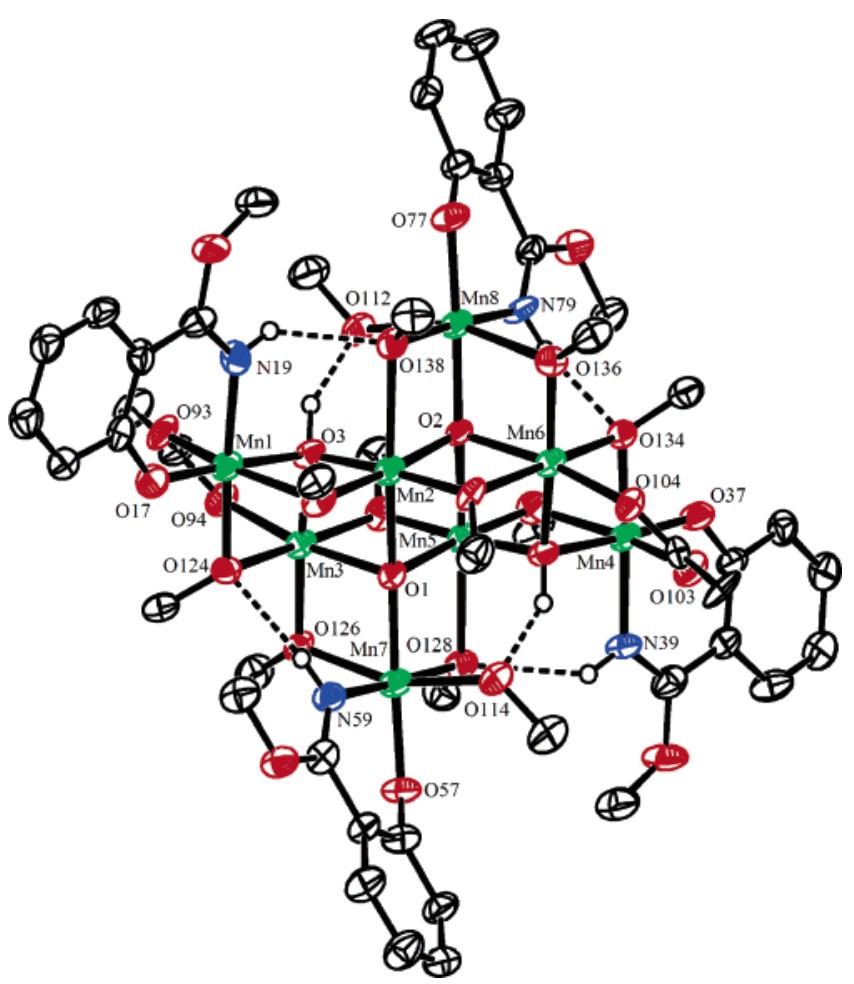

Figure 3. ORTEP representation of the molecular structure of $\mathbf{4}$ at $50 \%$ probability. Hydrogen atoms not involved in hydrogen bonding are omitted for clarity.

Mesalim ligands. The centrosymmetric complex comprises two groups of $\mathrm{Mn}_{3}$ clusters, and the core of the molecule can be regarded as a dimer of trimers joined together by oxide, methoxide, and carboxylate bridges. On the basis of charge considerations, all six manganese centers are manganese(III), which is confirmed by the elongated octahedral geometries observed for each six-coordinate manganese ion, typical for Jahn-Teller (JT) distorted $\mathrm{d}^{4}$ systems. The four

6716 Inorganic Chemistry, Vol. 45, No. 17, 2006 


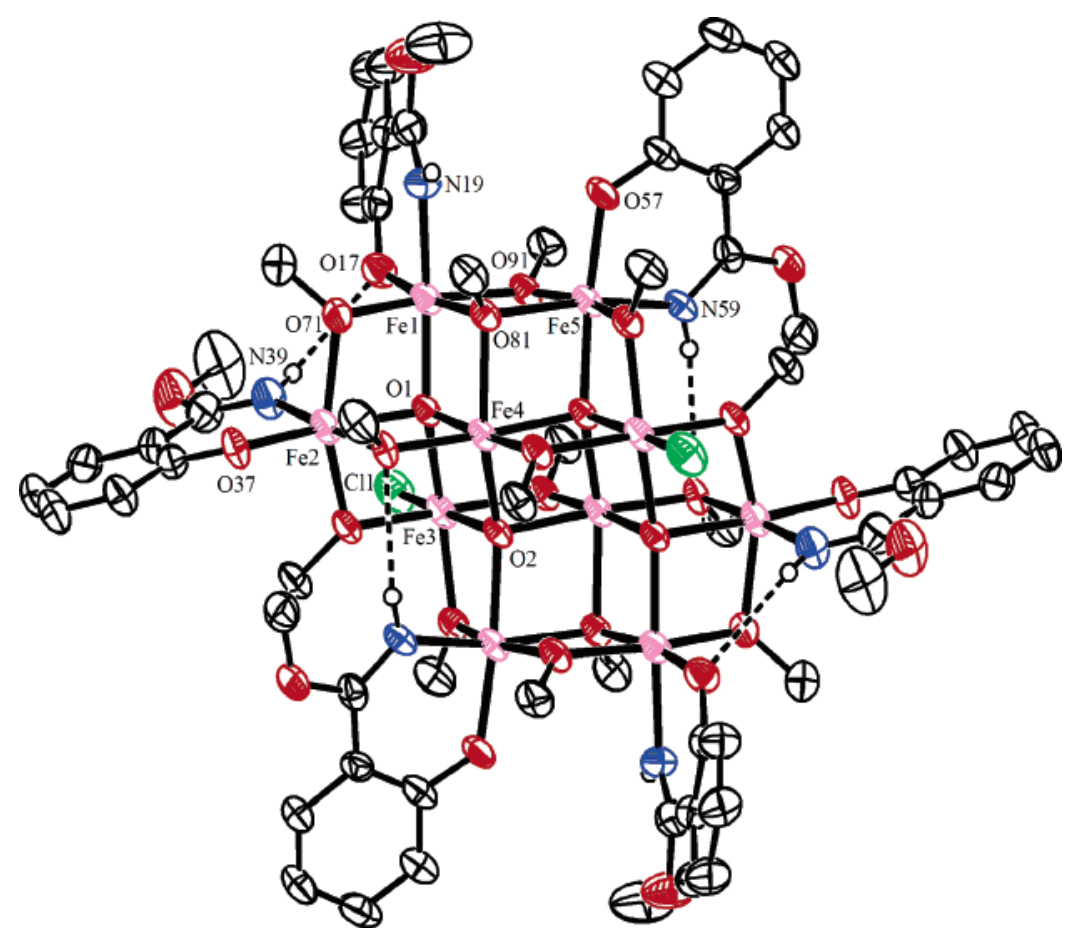

Figure 4. ORTEP representation of the molecular structure of $\mathbf{5}$ at 50\% probability. Hydrogen atoms not involved in hydrogen bonding are omitted for clarity.

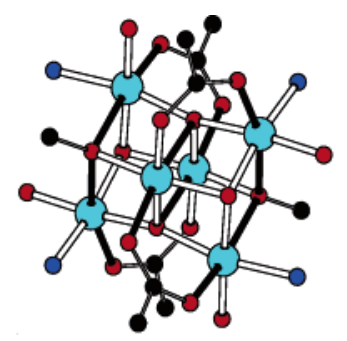

A

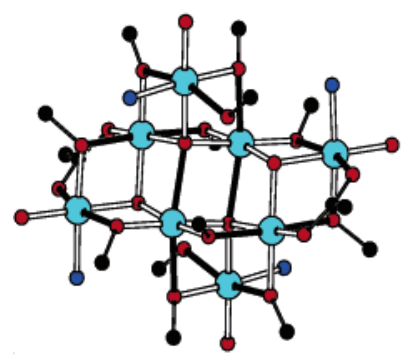

B

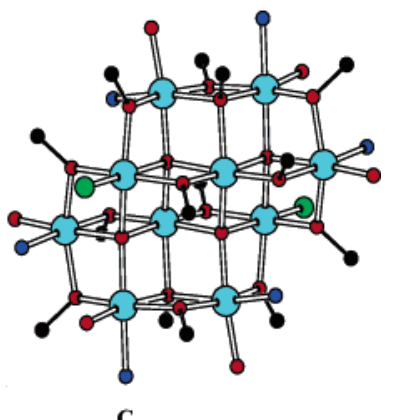

Figure 5. PLUTON projections of the cores of complexes $3\left[\mathrm{Mn}_{6} \mathrm{O}_{6}\right]$ (A), $4\left[\mathrm{Mn}_{8} \mathrm{O}_{14}\right](\mathrm{B})$, and $\mathbf{5}\left[\mathrm{Fe}_{10} \mathrm{O}_{18}\right](\mathrm{C})$. The bold lines in panels $\mathrm{A}$ and $\mathrm{B}$ depict JT axes for the Mn(III) ions.

peripheral manganese ions are in an $\mathrm{NO}_{5}$ coordination environment, whereas the two central manganese ions have $\mathrm{O}_{6}$ chromophores.

Together with two $\mu_{4}$-oxide bridges, the two central manganese ions form the shared face between the two cubes. The two central $\mu_{4}$-oxides are each coordinated to two manganese ions at the corners of the double-cubane, in addition to the central manganese ions, in an unusual "sawhorse" geometry. At each outer face of the doublecubane, two manganese ions are bridged by a $\mu_{3}$-methoxide
Table 2. Selected Bond Distances $(\AA)$ for Complex 3

\begin{tabular}{llll}
\hline $\mathrm{Mn} 1-\mathrm{O} 1$ & $1.9471(17)$ & $\mathrm{Mn} 2-\mathrm{N} 39$ & $1.979(2)$ \\
$\mathrm{Mn} 1-\mathrm{O} 2$ & $1.9269(17)$ & $\mathrm{Mn} 2-\mathrm{O} 2^{a}$ & $1.9586(17)$ \\
$\mathrm{Mn} 1-\mathrm{O} 17$ & $1.8788(18)$ & $\mathrm{Mn} 3-\mathrm{O} 1$ & $1.8827(17)$ \\
$\mathrm{Mn} 1-\mathrm{O} 52$ & $2.1441(19)$ & $\mathrm{Mn} 3-\mathrm{O} 2$ & $2.3958(18)$ \\
$\mathrm{Mn} 1-\mathrm{O} 71$ & $2.2811(18)$ & $\mathrm{Mn} 3-\mathrm{O} 33$ & $1.9338(18)$ \\
$\mathrm{Mn} 1-\mathrm{N} 19$ & $1.986(2)$ & $\mathrm{Mn} 3-\mathrm{O} 63$ & $2.1507(18)$ \\
$\mathrm{Mn} 2-\mathrm{O} 1$ & $1.9172(18)$ & $\mathrm{Mn} 3-\mathrm{O} 2^{a}$ & $1.9357(17)$ \\
Mn2-O37 & $1.8632(18)$ & $\mathrm{Mn3}-\mathrm{O} 71^{a}$ & $1.9016(18)$ \\
Mn2-O71 & $2.3715(18)$ & $\mathrm{Mn} 2-\mathrm{O} 62$ & $2.1632(19)$
\end{tabular}

${ }^{a}$ Symmetry code: $-x,-y, 2-z$.

Table 3. Selected Bond Distances $(\AA)$ for Complex 4

\begin{tabular}{llll}
\hline $\mathrm{Mn} 1-\mathrm{O} 3$ & $1.933(6)$ & $\mathrm{Mn} 3-\mathrm{O} 124$ & $2.163(7)$ \\
$\mathrm{Mn} 1-\mathrm{O} 17$ & $1.862(7)$ & $\mathrm{Mn} 3-\mathrm{O} 126$ & $1.883(5)$ \\
$\mathrm{Mn} 1-\mathrm{O} 93$ & $2.217(8)$ & $\mathrm{Mn} 3-\mathrm{O} 130$ & $2.150(6)$ \\
$\mathrm{Mn} 1-\mathrm{O} 122$ & $2.236(7)$ & $\mathrm{Mn} 5-\mathrm{O} 1$ & $1.967(6)$ \\
$\mathrm{Mn} 1-\mathrm{O} 124$ & $1.923(6)$ & $\mathrm{Mn} 5-\mathrm{O} 2$ & $2.305(5)$ \\
$\mathrm{Mn} 1-\mathrm{N} 19$ & $1.996(8)$ & $\mathrm{Mn} 5-\mathrm{O} 4$ & $1.952(6)$ \\
$\mathrm{Mn} 2-\mathrm{O} 1$ & $2.295(5)$ & $\mathrm{Mn} 5-\mathrm{O} 128$ & $2.249(5)$ \\
$\mathrm{Mn} 2-\mathrm{O} 2$ & $1.957(6)$ & $\mathrm{Mn} 5-\mathrm{O} 130$ & $1.886(6)$ \\
$\mathrm{Mn} 2-\mathrm{O} 3$ & $1.952(6)$ & $\mathrm{Mn} 5-\mathrm{O} 132$ & $1.895(6)$ \\
$\mathrm{Mn} 2-\mathrm{O} 122$ & $1.889(7)$ & $\mathrm{Mn} 7-\mathrm{O} 1$ & $1.911(5)$ \\
$\mathrm{Mn} 2-\mathrm{O} 138$ & $2.260(5)$ & $\mathrm{Mn} 7-\mathrm{O} 57$ & $1.885(6)$ \\
$\mathrm{Mn} 2-\mathrm{O} 140$ & $1.881(6)$ & $\mathrm{Mn} 7-\mathrm{O} 114$ & $2.331(7)$ \\
$\mathrm{Mn} 3-\mathrm{O} 1$ & $2.000(6)$ & $\mathrm{Mn} 7-\mathrm{O} 126$ & $2.273(6)$ \\
$\mathrm{Mn} 3-\mathrm{O} 3$ & $1.907(5)$ & $\mathrm{Mn} 7-\mathrm{O} 128$ & $1.916(6)$ \\
Mn3-O94 & $2.012(7)$ & $\mathrm{Mn} 7-\mathrm{N} 59$ & $2.000(8)$
\end{tabular}

group and a "normal $\mathrm{sp}^{3}$ type" $\mu_{3}$-oxide. Each of the peripheral manganese ions is connected to a third, central manganese ion, via a bridging carboxylate group. Finally, the octahedral coordination environment of the peripheral manganese ions is completed by coordination of the bidentate Mesalim ligand in such a way that for $\mathrm{Mn} 1$ the imine nitrogen is trans to a $\mu_{3}$-oxide, while for Mn2 the imine nitrogen is trans to a $\mu_{4}$-oxide. In the PLUTON projection of the core of the molecule shown in Figure 5A the JT axes of the manganese(III) ions are emphasized with bold black 
Table 4. Selected Bond Distances $(\AA)$ for Complex 5

$\begin{array}{llll}\mathrm{Fe} 1-\mathrm{O} 1 & 1.970(3) & \mathrm{Fe} 3-\mathrm{O} 101 & 2.014(3) \\ \mathrm{Fe} 1-\mathrm{O} 17 & 1.921(3) & \mathrm{Fe} 3-\mathrm{O} 121 & 2.052(3) \\ \mathrm{Fe} 1-\mathrm{O} 71 & 2.016(3) & \mathrm{Fe} 3-\mathrm{O} 131 & 1.998(3) \\ \mathrm{Fe} 1-\mathrm{O} 11 & 2.118(3) & \mathrm{Fe} 4-\mathrm{O} 1 & 2.082(3) \\ \mathrm{Fe} 1-\mathrm{O} 91 & 1.988(3) & \mathrm{Fe} 4-\mathrm{O} 2 & 1.944(3) \\ \mathrm{Fe} 1-\mathrm{N} 19 & 2.098(3) & \mathrm{Fe} 4-\mathrm{O} 81 & 2.119(3) \\ \mathrm{Fe} 2-\mathrm{O} 1 & 2.081(3) & \mathrm{Fe} 4-\mathrm{O} 111 & 1.998(3) \\ \mathrm{Fe} 2-\mathrm{O} 37 & 1.909(3) & \mathrm{Fe} 4-\mathrm{O} 2^{a} & 2.066(2) \\ \mathrm{Fe} 2-\mathrm{O} 71 & 2.002(3) & \mathrm{Fe} 4-\mathrm{O} 121^{a} & 1.970(3) \\ \mathrm{Fe} 2-\mathrm{O} 101 & 1.976(3) & \mathrm{Fe} 5-\mathrm{O} 2^{a} & 1.988(2) \\ \mathrm{Fe} 2-\mathrm{O} 111 & 2.064(3) & \mathrm{Fe} 5-\mathrm{O} 57 & 1.923(3) \\ \mathrm{Fe} 2-\mathrm{N} 39 & 2.106(3) & \mathrm{Fe} 5-\mathrm{O} 131^{a} & 2.006(3) \\ \mathrm{Fe} 3-\mathrm{Cl1} & 2.3064(12) & \mathrm{Fe} 5-\mathrm{N} 59 & 2.067(3) \\ \mathrm{Fe} 3-\mathrm{O} 1 & 2.017(3) & \mathrm{Fe} 5-\mathrm{O} 81 & 2.119(3) \\ \mathrm{Fe} 3-\mathrm{O} 2 & 2.099(2) & \mathrm{Fe} 5-\mathrm{O} 91 & 2.014(3) \\ { }^{a} \text { Symmetry code: } & 1-x,-y, 1-z . & & \end{array}$

lines. The JT axes of the peripheral manganese ions $\mathrm{Mn} 1$ and $\mathrm{Mn} 2$ lie along the line from the carboxylate oxygen to the $\mu_{3}$-methoxide, avoiding the oxygen or nitrogen from the ligand, and are therefore perpendicular to each other. The $\mathrm{JT}$ axis of the Mn3 ion, which is along $\mathrm{O} 2-\mathrm{Mn} 3-\mathrm{O} 63$, is parallel to that of Mn2 (along O62-Mn2-O71). The Mn. $\cdot \cdot \mathrm{Mn}$ distances are in the range of 2.81-3.35 $\AA$. The longest distance of $3.35 \AA$ is found in the central Mn3-Mn3a pair with two bridging $\mu_{4}$-oxo ions. The shortest distances of 2.81 and $2.96 \AA$ are found for $\mathrm{Mn} 2-\mathrm{Mn} 3$ and $\mathrm{Mn} 1-\mathrm{Mn} 3$, respectively, each pair with three bridging groups, a $\mu_{3}$-oxo, a $\mu_{4}$-oxo, and a bridging acetate group. The remaining $\mathrm{Mn}$ - Mn pairs, which are bridged by one $\mu_{3}$-oxo and one $\mu_{3}$ methoxo group have distances in the range of 3.05-3.21 $\AA$.

Two types of hydrogen bonds are present within the cluster (Figure 2). Details of the hydrogen-bonding interactions are summarized in Table 5. The imine group of the Mesalim ligand coordinated to $\mathrm{Mn} 2$ forms a hydrogen bond with the phenolate oxygen of the neighboring Mesalim coordinated to $\mathrm{Mn} 1(\mathrm{~N} 39 \cdots \mathrm{O} 17=3.09 \AA)$. The imine group of the Mesalim ligand bound to Mn1 forms a hydrogen bond with

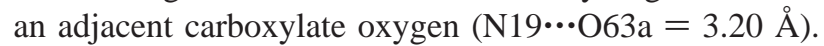

A detailed description of $\mathbf{4}$ has been given elsewhere. ${ }^{20}$ Structural analysis of $\mathbf{4}$ shows the compound to consist of neutral clusters, containing $8 \mathrm{Mn}(\mathrm{III})$ ions, $2 \mu_{4} \mathrm{O}^{2-}, 2 \mu_{3^{-}}$ $\mathrm{OH}^{-}, 10 \mu-\mathrm{OMe}^{-}, 2$ terminal $\mathrm{OMe}^{-}, 2 \mathrm{OAc}^{-}$anions, and 4 terminal anionic Mesalim ligands, with the cluster having noncrystallographic inversion symmetry. An alternative description of the complex would involve two terminal $\mathrm{MeOH}$ instead of $\mathrm{OMe}^{-}$and two $\mu_{3}-\mathrm{O}^{2-}$ instead of $\mathrm{OH}^{-}$. The hydroxo oxygen $\mathrm{O} 3$ that is coordinated to $\mathrm{Mn} 1$ forms a hydrogen bond with the methoxo oxygen $\mathrm{O} 112$ coordinated to $\mathrm{Mn} 8$, and similar description would apply to the symmetric

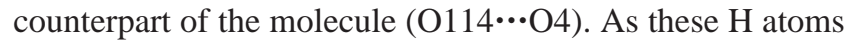
could not be located on difference Fourier maps, it cannot be confirmed if the hydrogen atom exists as a proton on the hydroxo group or on the methanol molecule.

The manganese ions in the $\mathrm{Mn}_{8}$ cluster have pseudooctahedral geometries. As expected, all $\mathrm{Mn}$ (III) ions present elongated JT axes, which is known to result in a negative value of the axial zero-field splitting parameter. ${ }^{27}$ In the

(27) Gerritsen, H. J.; Sabisky, E. S. Phys. Rev. 1963, 132, 1507-1512.
PLUTON projection of the core of the molecule shown in Figure 5B, the JT axes of the manganese(III) ions are emphasized with bold black lines. Each of the three groups of parallel JT axes are approximately orthogonal to the other two orientations and a resulting significant magnetic anisotropy can thus be expected.

The Mn $\cdots$ Mn distances are in the range of 2.94-3.25. The distances fall in three main groups, the longest distance of $3.25 \AA$ is found in the central Mn2-Mn5 pair with two bridging oxo ions. The shortest distances of $2.94 \AA$ are found between the peripheral Mn1-Mn3 and Mn4-Mn6, having three bridging groups: (hydr)oxo, methoxo and acetato. The remaining Mn...Mn pairs, which are bridged by one oxo and one methoxo group have distances in the range of 3.03$3.09 \AA$.

The hydrogen bonds present within the cluster are shown in Figure 3. Details of the hydrogen-bonding interactions are summarized in Table 5. In addition to the hydrogen-bond interaction between the terminal methoxides and the hydroxide ions, as discussed above, the imine group of the Mesalim ligand coordinated to Mn1, Mn8, Mn4, and Mn7 form a hydrogen bond with the methoxo oxygen coordinated to $\mathrm{Mn} 8, \mathrm{Mn} 4, \mathrm{Mn} 7$, and $\mathrm{Mn} 1$, respectively ( $\mathrm{D}-\mathrm{H} \cdots \mathrm{A}=$ $2.93-3.06 \AA$ ).

A molecule of $\mathbf{5}$ is located on a crystallographic inversion center and consists of ten $\mathrm{Fe}(\mathrm{III})$ cations, $4 \mu_{4}-\mathrm{O}^{2-}$ anions, 2 $\mu_{3}-\mathrm{OMe}^{-}$anions, $12 \mu-\mathrm{OMe}^{-}$anions, $2 \mathrm{Cl}^{-}$anions, and 6 terminal anionic Mesalim ligands. There are four different types of distorted octahedral coordination environments for the five iron ions in the asymmetric unit, $\left[\mathrm{Fe}(\mu-\mathrm{OMe})_{3}\left(\mu_{4}-\right.\right.$ $\mathrm{O})(\mathrm{L})],\left[\mathrm{Fe}(\mu-\mathrm{OMe})_{2}\left(\mu_{3}-\mathrm{OMe}\right)\left(\mu_{4}-\mathrm{O}\right)(\mathrm{L})\right],\left[\mathrm{Fe}(\mu-\mathrm{OMe})_{2}\left(\mu_{3^{-}}\right.\right.$ $\left.\mathrm{OMe})\left(\mu_{4}-\mathrm{O}\right)_{3}\right]$, and $\left[\mathrm{Fe}(\mu-\mathrm{OMe})_{3}\left(\mu_{4}-\mathrm{O}\right)_{2} \mathrm{Cl}\right]$. The phenolate oxygen donors of the ligands are bound more tightly to the iron centers than the other coordinating oxygen ions. Thus, $\mathrm{Fe} 1-\mathrm{O} 17, \mathrm{Fe} 2-\mathrm{O} 37$ and $\mathrm{Fe} 5-\mathrm{O} 57$ bond distances are 1.921(3), 1.909(3), and 1.922(3) ̊, respectively, while the other $\mathrm{Fe}-$ oxo distances lie in the range of 1.943(3)-2.119(3) $\AA$. Pairs of iron neighbors are connected by two methoxo or oxo bridges. The distance between the iron ions is dependent on the bridging ligands and decreases in the order $2 \mu$-methoxo $(3.21 \AA$ ) $>1 \mu$-methoxo and $1 \mu$-oxo (range 3.05-3.15 $\AA$ ) > two $\mu$-oxo (3.07 $\AA$ ).

There are two intramolecular hydrogen bonds present in the asymmetric unit of the complex (Figure 4, Table 5), one is formed by hydrogen bonding between the imine nitrogen of one of the Mesalim ligands and one of the methoxo bridges, and the other is formed between the imine nitrogen of one of the Mesalim ligands and the phenoxo oxygen of a neighboring Mesalim ligand. One of the $\mathrm{N}-\mathrm{H}$ groups does not donate an $\mathrm{H}$-bond. The $\left[\mathrm{Fe}_{10} \mathrm{O}_{18}\right]$ core of complex $\mathbf{5}$ can be described as consisting of $10\left[\mathrm{Fe}_{3} \mathrm{O}_{4}\right]$ partial cubane units, the outer eight being doubly face-sharing and the central two being triply face-sharing.

\section{Discussion of the Crystal Structures}

Complex $\mathbf{3}$ contains an isolated face-sharing double-cubane core that is rare in manganese or iron cluster chemistry. The $\left[\mathrm{M}_{4} \mathrm{O}_{2}\right]$ (butterfly), $\left[\mathrm{M}_{3} \mathrm{O}_{4}\right]$ (partial cubane) and $\left[\mathrm{M}_{4} \mathrm{O}_{4}\right]$ 
Table 5. Hydrogen Bond Donor-Acceptor Distances ( $\AA$ ) for Complexes 3, 4, and 5

\begin{tabular}{|c|c|c|c|c|c|}
\hline \multicolumn{2}{|c|}{3} & \multicolumn{2}{|c|}{4} & \multicolumn{2}{|c|}{5} \\
\hline $\mathrm{N} 19-\mathrm{H} 19 \cdot \cdots \mathrm{O}^{2} 3^{a}$ & $3.200(3)$ & $\mathrm{O} 3-\mathrm{H} 3 \cdots \mathrm{O} 112$ & $2.643(9)$ & 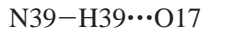 & $3.143(5)$ \\
\hline 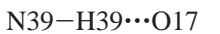 & $3.091(3)$ & $\mathrm{O} 4-\mathrm{H} 4 \cdots \mathrm{O} 114$ & $2.658(9)$ & $\mathrm{N} 59-\mathrm{H} 59 \cdots \mathrm{O} 111^{b}$ & $3.399(5)$ \\
\hline & & 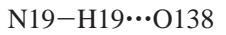 & $2.940(9)$ & & \\
\hline & & 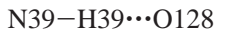 & $3.064(8)$ & & \\
\hline & & 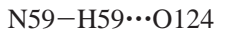 & $2.994(10)$ & & \\
\hline & & $\mathrm{N} 79-\mathrm{H} 79 \cdots \mathrm{O} 134$ & $2.931(9)$ & & \\
\hline
\end{tabular}

${ }^{a}$ Symmetry operations: $-x,-y, 2-z \cdot{ }^{b}$ Symmetry operations: $1-x,-y, 1-z$.

(cubane), $\left[\mathrm{M}_{4} \mathrm{O}_{6}\right]$ (adamantane) are commonly occurring subunits in high-nuclearity manganese and iron clusters. Face-sharing double-cubane subunits are commonly found in polyoxo-molybdate or -vanadate chemistry, ${ }^{28-30}$ and are found in few manganese and iron clusters. ${ }^{31-33}$ Isolated, welldefined face-sharing double-cubane $\left[\mathrm{M}_{6} \mathrm{O}_{6}\right]$ units are only found in a few sodium, ${ }^{34,35}$ potassium, ${ }^{36}$ and calcium ${ }^{37}$ complexes. The isolated $\left[\mathrm{Mn}_{6} \mathrm{O}_{6}\right]$ core of complex 3 is the first to be observed in a transition metal oxide cluster.

Interestingly, a mixed-metal $\mathrm{Ru}_{4} \mathrm{Mo}_{4} \mathrm{O}_{16}$ cluster has been studied by multinuclear NMR by Artero et al., ${ }^{38}$ and it has been shown to exist in solution as two isomers, the windmilllike form (similar to complex 4) and a triple-cubane form (similar to complex 3), while the double cubane cluster $\mathrm{Ru}_{4} \mathrm{~W}_{2} \mathrm{O}_{10}$ was found to be formed as a byproduct of the synthesis of the windmill-like cluster $\mathrm{Ru}_{4} \mathrm{~W}_{4} \mathrm{O}_{16}$. In the course of the synthesis of complexes $\mathbf{3}$ and $\mathbf{4}$, it was found that by changing the $\mathrm{M} / \mathrm{L}$ ratio from $1: 3$ to $2: 1$ or $2: 3$, a crystalline product was obtained, the IR of which showed the presence of a mixture of $\mathbf{3}$ and $\mathbf{4}$. However, by changing the solvents for crystallization, the two clusters have been successfully isolated. The $\left[\mathrm{M}_{3} \mathrm{O}_{4}\right]$ unit observed in complexes $\mathbf{4}$ and $\mathbf{5}$ is a subfragment that is commonly encountered in highnuclearity manganese and iron clusters. However, it is also worth noting that octanuclearity in purely $\mathrm{Mn}(\mathrm{III})$ oxo/ carboxylato compounds is quite rare, ${ }^{15,39-42}$ and the core

(28) Duraismay, T.; Ramanan, A.; Vittal, J. J. J. Mater. Chem. 1999, 9, 763-767.

(29) Biagioli, M.; Strinna-Erre, L.; Micera, G.; Panzanelli, A.; Zema, M. Inorg. Chem. Commun. 1999, 2, 214-217.

(30) Pessoa, J. C.; Duarte, M. T.; Gillard, R. D.; Madeira, C.; Matias, P. M.; Tomaz, I. J. Chem. Soc., Dalton Trans. 1998, 4015-4020.

(31) Taft, K. L.; Papaefthymiou, G. C.; Lippard, S. J. Inorg. Chem. 1994, 33, $1510-1520$.

(32) Sun, Z. M.; Gantzel, P. K.; Hendrickson, D. N. Inorg. Chem. 1996, $35,5,6640-6641$

(33) Cavaluzzo, M.; Chen, Q.; Zubieta, J. J. Chem. Soc., Chem. Commun. 1993, 131-133.

(34) Hogerheide, M. P.; Ringelberg, S. N.; Janssen, M. D.; Boersma, J.; Spek, A. L.; van Koten, G. Inorg. Chem. 1996, 35, 1195-1200.

(35) Kunert, M.; Dinjus, E.; Nauck, M.; Sieler, J. Chem. Ber., Recl. 1997, $130,1461-1465$.

(36) Boyle, T. J.; Andrews, N. L.; Rodriguez, M. A.; Campana, C.; Yiu, T. Inorg. Chem. 2003, 42, 5357-5366.

(37) Turova, N. Y.; Turevskaya, E. P.; Kessler, V. G.; Yanovsky, A. I.; Struchkov, Y. T. J. Chem. Soc., Chem. Commun. 1993, 21-23.

(38) Artero, V.; Proust, A.; Herson, P.; Thouvenot, R.; Gouzerh, P. Chem. Commun. 2000, 883-884.

(39) Tsai, H. L.; Wang, S. Y.; Folting, K.; Streib, W. E.; Hendrickson, D. N.; Christou, G. J. Am. Chem. Soc. 1995, 117, 2503-2514.

(40) Wang, S.; Tsai, H. L.; Folting, K.; Martin, J. D.; Hendrickson, D. N.; Christou, G. J. Chem. Soc., Chem. Commun. 1994, 671-673.

(41) Libby, E.; Folting, K.; Huffman, C. J.; Huffman, J. C.; Christou, G. Inorg. Chem. 1993, 32, 2549-2556.

(42) Rajaraman, G.; Murugesu, M.; Sanudo, E. C.; Soler, M.; Wernsdorfer, W.; Helliwell, M.; Muryn, C.; Raftery, J.; Teat, S. J.; Christou, G.; Brechin, E. K. J. Am. Chem. Soc. 2004, 126, 15445-15457. present in $\mathbf{4}$ has not been reported so far. Another unusual octanuclear manganese cluster without carboxylate groups but with a simple bridging ligand has recently been reported, the structure of which is based on a cubane $\left[\mathrm{Mn}_{4} \mathrm{O}_{4}\right]$ core with four additional manganese ions attached to the oxo groups. ${ }^{43}$ The central $\mathrm{Mn}_{6}$ core in complex $\mathbf{4}$ and the central $\mathrm{Fe}_{6}$ core in complex 5 resembles that of the hexamanganese complex reported by Tuchagues et al..$^{44}$ The structures of complexes $\mathbf{4}$ and $\mathbf{5}$ are very similar to each other. In fact, it can be easily visualized that the $\left[\mathrm{Mn}_{8} \mathrm{O}_{14}\right]$ core of complex 4 can be derived from the $\left[\mathrm{Fe}_{10} \mathrm{O}_{18}\right]$ core of complex 5 by removal of two metal atoms, $\mathrm{Fe} 5$ and $\mathrm{Fe} 5 \mathrm{a}$, and four oxygen atoms. The structures of complexes $\mathbf{4}$ and $\mathbf{5}$ are also very similar to that of the heptanuclear manganese cluster $\left[\mathrm{Mn}_{7^{-}}\right.$ $\left.(\mathrm{OMe})_{12}(\mathrm{dbm})_{6}\right]^{45}$ The difference is that complexes $\mathbf{4}$ and $\mathbf{5}$ contain three close-packed layers of oxygen atoms and two layers of metal atoms, as compared to two close-packed layers of oxygen atoms and a single layer of manganese atoms in the heptanuclear cluster.

Three complexes with the $\left[\mathrm{Fe}_{10} \mathrm{O}_{18}\right]$ core similar to that of complex $\mathbf{5}$ have been reported in the literature: $\left[\mathrm{Fe}_{10} \mathrm{O}_{4}\right.$ $\left.(\mathrm{OMe})_{16}(\mathrm{dbm})_{6}\right](\mathrm{Hdbm}=$ dibenzoylmethane $){ }_{,}^{46}\left[\mathrm{Fe}_{10} \mathrm{Cl}_{8} \mathrm{O}_{4}-\right.$ $\left.(\mathrm{OMe})_{14}(\mathrm{MeOH})_{6}\right] \cdot 2 \mathrm{MeOH},{ }^{47}$ and $\left[(\mathrm{HL})_{12} \mathrm{Fe}_{10} \mathrm{Na}_{4}\left(\mu_{4}-\mathrm{O}\right)_{4}\left(\mu_{3^{-}}\right.\right.$ $\left.\mathrm{OH})_{2}(\mathrm{dme})_{2}(\mathrm{EtOH})_{2}\right] \cdot 2 \mathrm{dme} \cdot 8 \mathrm{EtOH}$, where $\mathrm{H}_{3} \mathrm{~L}=4$-tertbutyl-2,6-bis(hydroxymethyl)phenol and dme $=1,2$-dimethoxyethane. ${ }^{13}$ Structurally, the $\left[\mathrm{Fe}_{10} \mathrm{O}_{18}\right]$ cores of these molecules can be considered as fragments of an iron oxide (wustite) or hydroxide (lepidocrocite) phase: the oxygen atoms of the cores are arranged in cubic close-packed layers with the iron atoms occupying the octahedral interstices. ${ }^{48}$ Another complex worth mentioning here is a $\mathrm{Ti}_{10} \mathrm{O}_{32}$ cluster that is analogous to $\mathbf{5}{ }^{49}$

Magnetism. Variable-temperature magnetic susceptibility data were collected on bulk polycrystalline samples of complexes 3, 4, and 5 under a magnetic field of $0.1 \mathrm{~T}$. Plots of $\chi_{\mathrm{M}} T$ and $\chi_{\mathrm{M}}{ }^{-1}$ vs $T$ are given in Figure 6A and Figure 6B for complex $\mathbf{3}$ and $\mathbf{5}$, respectively, where $\chi_{\mathrm{M}}$ is the molar magnetic susceptibility. The value of $\chi_{\mathrm{M}} T$ per $\left[\mathrm{Mn}_{6}\right]$ in $\mathbf{3}$

(43) Tanase, S.; Aromí, G.; Bouwman, E.; Kooijman, H.; Spek, A. L.; Reedijk, J. Chem. Commun. 2005, 3147-3149.

(44) Xia, X. P.; Verelst, M.; Daran, J. C.; Tuchagues, J. P. J. Chem. Soc., Chem. Commun. 1995, 2155-2157.

(45) Abbati, G. L.; Cornia, A.; Fabretti, A. C.; Caneschi, A.; Gatteschi, D. Inorg. Chem. 1998, 37, 3759-3766.

(46) Caneschi, A.; Cornia, A.; Fabretti, A. C.; Gatteschi, D. Angew. Chem., Int. Ed. Engl. 1996, 34, 2716-2718.

(47) Asirvatham, S.; Khan, M. A.; Nicholas, K. M. Inorg. Chem. 2000 , 39, 2006-2007.

(48) Caneschi, A.; Cornia, A.; Fabretti, A. C.; Gatteschi, D.; Malavasi, W. Inorg. Chem. 1995, 34, 4660-4668.

(49) Day, V. W.; Eberspacher, T. A.; Klemperer, W. G.; Park, C. W.; Rosenberg, F. S. J. Am. Chem. Soc. 1991, 113, 8190-8192. 
Godbole et al.
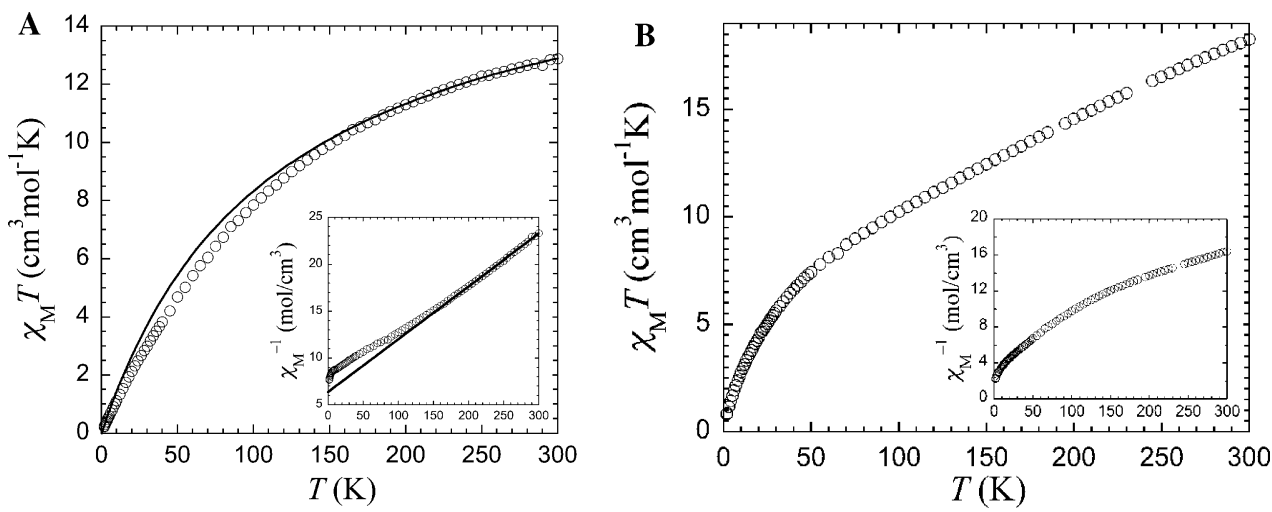

Figure 6. (A) Temperature dependence of the product $\chi_{\mathrm{M}} T$ and $\chi_{\mathrm{M}}{ }^{-1}$ for 3 at $0.1 \mathrm{~T}$. The solid lines represent the best fit to a Curie-Weiss law. (B) Temperature dependence of the product $\chi_{\mathrm{M}} T$ and $\chi_{\mathrm{M}}{ }^{-1}$ for 5 at $0.1 \mathrm{~T}$.
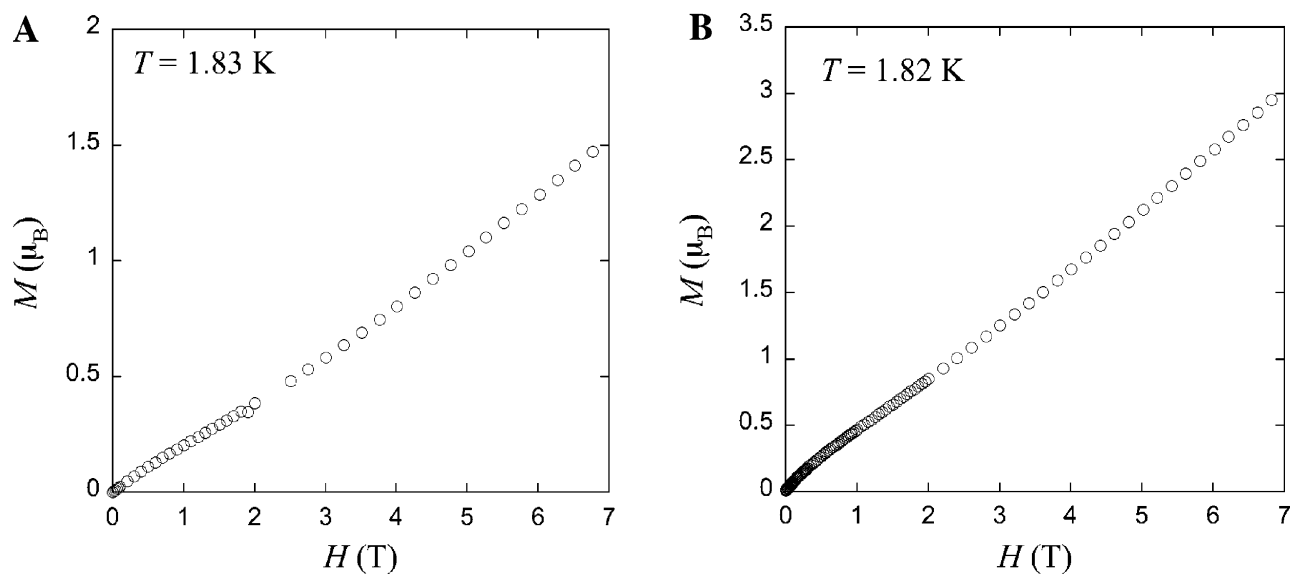

Figure 7. (A) Magnetization vs field data for complex 3 at $1.83 \mathrm{~K}$. The small values of $M$ at low fields are in agreement with an $S_{\mathrm{T}}=0$ ground state not fully populated at this temperature. The increase at the highest fields is likely due to the population of higher spin low-lying excited states. (B) Magnetization vs field data for complex 5 at $1.82 \mathrm{~K}$. The small values of $M$ at low fields are in agreement with an $S_{\mathrm{T}}=0$ ground state not fully populated at this temperature. The increase at the highest fields is likely due to the population of higher spin low-lying excited states.

drops from $12.9 \mathrm{~cm}^{3} \mathrm{~mol}^{-1} \mathrm{~K}$ at $300 \mathrm{~K}$ to $0.23 \mathrm{~cm}^{3} \mathrm{~mol}^{-1} \mathrm{~K}$ at $2 \mathrm{~K}$, with an acceleration of the decrease below $200 \mathrm{~K}$. The value at room temperature is much smaller than expected for an uncoupled $\left[\mathrm{Mn}_{6}^{\mathrm{III}}\right]$ cage with $g=2\left(18 \mathrm{~cm}^{3} \mathrm{~mol}^{-1}\right.$ $\mathrm{K})$, which together with the decrease upon cooling reveals the presence of antiferromagnetic interactions within the cluster. Indeed, both plots follow a Curie-Weiss behavior above ca. $150 \mathrm{~K}$, with $C=17.78 \mathrm{~cm}^{3} \mathrm{~mol}^{-1} \mathrm{~K}$ and $\theta=$ $-112 \mathrm{~K}$. The Curie constant is consistent with six $\mathrm{Mn}(\mathrm{III})$ ions with a $g$ value of 1.98 , while the negative Weiss constant indicates the presence of dominant antiferromagnetic interactions (of the order of $\theta / S^{2}=30 \mathrm{~K}$ ) between the spin carriers.

Below $150 \mathrm{~K}$, the data deviate significantly from the Curie-Weiss law, suggesting that a magnetic model considering the different magnetic pathways within the $\left[\mathrm{Mn}_{6} \mathrm{O}_{6}\right]$ core should be used to analyze the low-temperature data. Syn-syn axial acetate bridges are expected to couple the $\mathrm{Mn}$ (III) centers antiferromagnetically, while oxo and hydroxo bridges may yield weak ferromagnetic coupling, as in the well-known distorted cubane series $\left[\mathrm{Mn}_{4} \mathrm{O}_{3} \mathrm{X}\left(\mathrm{O}_{2} \mathrm{CR}\right)_{3}(\mathrm{dbm})_{3}\right]$ $\left(\mathrm{X}=\mathrm{F}^{-}, \mathrm{Cl}^{-}-\mathrm{OH}^{-}\right.$, etc.; $\mathrm{R}=\mathrm{Me}, \mathrm{Et}, \mathrm{Ph} ; \mathrm{dbm}^{-}=$the anion of dibenzoylmethane), ${ }^{50}$ to moderate antiferromagnetic

(50) Aubin, S. M. J.; Dilley, N. R.; Pardi, L.; Krzystek, J.; Wemple, M. W.; Brunel, L. C.; Maple, M. B.; Christou, G.; Hendrickson, D. N. J. Am. Chem. Soc. 1998, 120, 4991-5004. coupling. Although the geometry of the bridge (mainly the $\mathrm{Mn}-\mathrm{O}-\mathrm{Mn}$ angle) probably controls the exchange coupling, no correlation has been reported as yet in the literature with $\mathrm{Mn}(\mathrm{III})$. In addition, it was shown that even terminal ligands have to be considered because their influence on the energy of the metal d orbitals may change the energy difference with orbitals of the bridging ligand and therefore influence the strength of coupling. ${ }^{11,16}$ A quantitative analysis of the magnetic properties of $\mathbf{3}$ is thus complicated by the presence of five independent magnetic exchange interactions, whose pre-evaluation is not straightforward. In addition, the full magnetic coupling scheme has no analytical solution and requires the use of full-matrix diagonalization, which was unsuccessful. At low temperatures $(<50 \mathrm{~K})$, zero-field splitting of the remaining $S>1 / 2$ states is also likely to take part in the sharper lowering of $\chi_{\mathrm{M}} T$. Nevertheless, it can be concluded that the spin ground state of complex $\mathbf{3}$ is $S_{\mathrm{T}}=0$, as confirmed by magnetization vs field measurements at $2 \mathrm{~K}$ that show extremely small values up to $7 \mathrm{~T}$ (Figure 7A).

Regarding complex 5, the value of the product $\chi_{\mathrm{M}} T$ at 300 $\mathrm{K}, 18.2 \mathrm{~cm}^{3} \mathrm{~mol}^{-1} \mathrm{~K}$, is much lower than expected for 10 uncoupled Fe(III) $S=5 / 2$ spins $\left(43.75 \mathrm{~cm}^{3} \mathrm{~mol}^{-1} \mathrm{~K}\right.$ for $g$ $=2$ ), indicative of the presence of strong antiferromagnetic exchange interactions among the spin carriers. Indeed, $\chi_{\mathrm{M}} T$ 


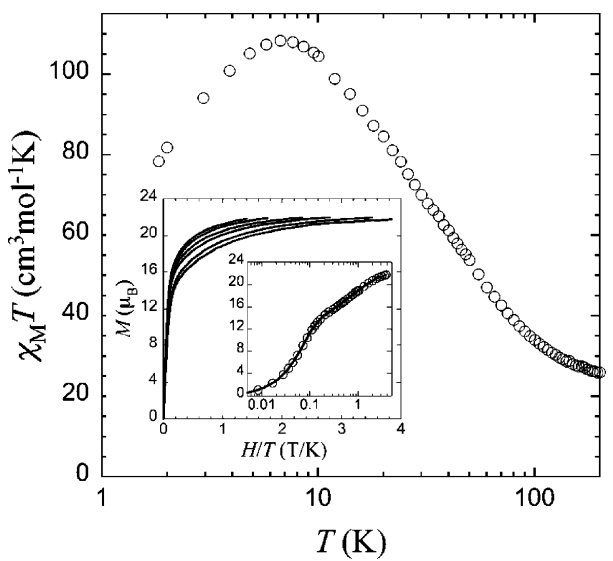

Figure 8. Plot of $\chi_{\mathrm{M}} T$ vs $T$ under $0.1 \mathrm{~T}$ for complex 4. Inset: reduced magnetization data as normal and semilog plots.

steadily decreases down to $8.05 \mathrm{~cm}^{3} \mathrm{~mol}^{-1} \mathrm{~K}$ at $60 \mathrm{~K}$ and further down to $0.82 \mathrm{~cm}^{3} \mathrm{~mol}^{-1} \mathrm{~K}$ at $1.8 \mathrm{~K}$. Oxo and hydroxo bridges such as those within the $\left[\mathrm{Fe}_{10} \mathrm{O}_{18}\right]$ core are expected to yield antiferromagnetic couplings of various strengths depending on their geometries, ${ }^{1}$ and likely active even at $300 \mathrm{~K}$, due to the high spin of Fe(III) ions. However, examination of the structure suggests that 10 independent magnetic exchange interactions should be taken into account to model the behavior of complex $\mathbf{5}$, precluding any simple analysis. Nevertheless, the observed behavior, with $\chi_{\mathrm{M}} T$ tending to 0 at low temperatures, and the very low values of magnetization at $2 \mathrm{~K}$, even at high fields (Figure 7B), point to an $S_{\mathrm{T}}=0$ ground state for the $\left[\mathrm{Fe}_{10}\right]$ aggregate.

Considering the moderate antiferromagnetic coupling observed in complex $\mathbf{3}$, a mixed-valent species possessing the same $\left[\mathrm{Mn}_{6} \mathrm{O}_{6}\right]$ core might result in high-spin molecules through noncompensated spins. This could possibly be achieved by electrochemical modification of the present cluster. In both complexes $\mathbf{3}$ and $\mathbf{5}$, the occurrence of dominant antiferromagnetic interactions arises as a result of the geometry of the oxo and hydroxo bridges within the core of the clusters. Other geometries with different exchange interactions can also be obtained with the ligand HMesalim, which in all cases acts as an outer protective shell. Complex 4, in which all the JT axes are parallel, is a good example (vide infra). The external uncoordinated $\mathrm{O}$ or $\mathrm{N}$ atoms present in $\mathbf{3}$ and $\mathbf{5}$ might be used to bind to additional metal ions, thus allowing for higher nuclearities or the creation of extended structures. In this sense, complexes $\mathbf{3}$ and $\mathbf{5}$ can be regarded as interesting building blocks for synthesizing new molecular magnets.

As previously communicated, the temperature dependence of $\chi_{\mathrm{M}} T$ for complex 4 (shown in Figure 8) indicates the presence of dominant ferromagnetic interactions among the $\left[\mathrm{Mn}_{8}\right]$ core, yielding a high-spin ground state. The value of $\chi_{\mathrm{M}} T$ at $300 \mathrm{~K}$ is in good agreement with the spin-only value for eight uncoupled $S=2$ spins, e.g., $24 \mathrm{~cm}^{3} \mathrm{~K} \mathrm{~mol}^{-1}$. (see Figure 8). Given the symmetry of the interaction scheme in 4, neither the Kambe method ${ }^{51}$ nor a numerical approach to evaluate the exchange parameters between the Mn(III) ions

(51) Kambe, K. J. Phys. Soc. Jpn. 1950, 5, 48-51. could be applied. Reduced magnetization increases rapidly at low fields up to a value of ca. $16 \mu_{\mathrm{B}}$ (in agreement with an $S_{\mathrm{T}}=8$ ground state), and then more smoothly, without reaching saturation at the highest field $(7 \mathrm{~T})$. Together with the lack of low-temperature saturation of the $\chi_{\mathrm{M}} T$ product, these data indicate that even at the experimental lowest temperature low-lying excited states are populated, impeding that the value of the spin ground state and its anisotropy parameter $D$ be determined as often done. ${ }^{52}$ A possible situation is that the spin ground state of complex $\mathbf{4}$ would be $S_{\mathrm{T}}=8$ but with very low-lying excited spin-states. An $S_{\mathrm{T}}=8$ ground state would indeed be in agreement with an expected ferromagnetic central Mn2-Mn5 interaction, ${ }^{53}$ while the rest of the Mn pairs are weakly antiferromagnetically coupled. Nevertheless, the highest value reached by $\chi_{\mathrm{M}} T$ (close to $108 \mathrm{~cm}^{3} \mathrm{~K} \mathrm{~mol}^{-1}$ ) is much higher than expected for an $S_{\mathrm{T}}=8$ ground state $\left(36 \mathrm{~cm}^{3} \mathrm{~K} \mathrm{~mol}^{-1}\right)$. Although this may be due to the population of low-lying excited states with higher spins, it may also indicate a higher-spin ground state. The fall of $\chi_{\mathrm{M}} T$ at low temperatures is then either a consequence of intramolecular competing antiferromagnetic and ferromagnetic interactions among Mn pairs (note that no significant intermolecular interactions have been observed in the crystal structure) and/or of magnetic anisotropy (ZFS).

Slow relaxation of the magnetization of $\mathbf{4}$ was studied using ac techniques. As expected for SMM, the ac susceptibilities are strongly frequency dependent (see Supporting Information), indicative of a slow magnetization-relaxation phenomenon. Remarkably, blocking temperatures can be observed in 4 at reasonable temperatures, i.e., above $3 \mathrm{~K}$ for frequencies higher than $500 \mathrm{~Hz}$, though a second relaxation mode at higher frequencies, aside from the main one is observed, and confirmed by the shape of Cole-Cole plots (Supporting Information). This observation can be ascribed to a small impurity or to intermolecular effects. ${ }^{54}$ The main relaxation time, $\tau$, can be determined from the maximum of $\chi^{\prime \prime}$ as a function of both temperature and frequency. In the temperature domain studied, the relaxation time follows the Arrhénius law with $\Delta k_{B}=36.0 \mathrm{~K}$ and $\tau_{0}$ $=4.39 \times 10^{-9} \mathrm{~s}$ (for $T>2.1 \mathrm{~K}$ ), indicating that the relaxation is thermally activated. As in many SMMs, it is likely that $\Delta$ corresponds in fact to an effective barrier, resulting from the short-cut of the thermal barrier by quantum tunneling of magnetization. In $\mathbf{4}$, the experimental energy barrier $\Delta_{\text {eff }} / k_{B}=36.0 \mathrm{~K}$ remains relatively large. The octanuclear core of $\mathbf{4}$ is thus a new addition to the still quite small number of metal ion cores in which this behavior has been observed at reasonably high temperatures.

\section{Concluding Remarks}

Despite the fact that the simple bidentate ligand HMesalim has been known for over 30 years, its coordination chemistry

(52) Vincent, J. B.; Christmas, C.; Chang, H. R.; Li, Q. Y.; Boyd, P. D. W.; Huffman, J. C.; Hendrickson, D. N.; Christou, G. J. Am. Chem. Soc. 1989, 111, 2086-2097.

(53) Miyasaka, H.; Clerac, R.; Ishii, T.; Chang, H. C.; Kitagawa, S.; Yamashita, M. J. Chem. Soc., Dalton Trans. 2002, 1528-1534.

(54) Boskovic, C.; Bircher, R.; Tregenna-Piggott, P. L. W.; Gudel, H. U.; Paulsen, C.; Wernsdorfer, W.; Barra, A. L.; Khatsko, E.; Neels, A.; Stoeckli-Evans, H. J. Am. Chem. Soc. 2003, 125, 14046-14058. 


\section{Godbole et al.}

has not been fully explored. In the present study, HMesalim has been found to give polynuclear clusters upon reaction with manganese or iron salts. Three novel, neutral manganese/ iron clusters - hexanuclear, octanuclear, and decanuclearhave been synthesized and structurally characterized. Although the bridging coordination mode is commonly observed for ligands containing phenoxo donors, including HEtsalim, ${ }^{19,55-57}$ the HMesalim ligand occupies terminal positions in these clusters. Nevertheless, the small size of the ligand plays an important role in the aggregation of the oxo- and methoxo-bridged clusters.

Variable-temperature magnetic studies show dominant antiferromagnetic interactions in the hexanuclear manganese and decanuclear iron complexes resulting in a zero-spin ground state and ferromagnetic interactions in the octanuclear manganese complex which exhibits SMM behavior. The study of the magnetic properties of this novel cluster has revealed a rather high-energy barrier allowing the observation of thermally activated relaxation above $3 \mathrm{~K}$. These observations point out the need for further thorough exploration of coordination chemistry of the ligand HMesalim, which represents an interesting new entry in the small list of

(55) Geiss, A.; Vahrenkamp, H. Eur. J. Inorg. Chem. 1999, 1793-1803.

(56) Shyu, H. L.; Wei, H. H.; Wang, Y. Inorg. Chim. Acta 1999, 290, $8-13$.

(57) Aono, T.; Wada, H.; Yonemura, M.; Furutachi, H.; Ohba, M.; Okawa, H. J. Chem. Soc., Dalton Trans. 1997, 3029-3034. chelating ligands used so far in the field of nanomagnets. The determination of the magnetic exchange interactions in these complexes has, however, not been possible due to their complex nature. The results in this paper demonstrate the potential of the HMesalim-like ligands in obtaining new topologies of metal clusters that could be a matter of interest for further synthetic and magnetochemical studies.

Acknowledgment. This work has been carried out within the framework of the Council for Chemical Sciences of The Netherlands Foundation for Scientific Research (CW-NWO), through a grant from the special program "Aspasia". X-ray crystallographic work was supported (A.L.S.) by the Council for the Chemical Sciences of The Netherlands Organization for Scientific research (CW-NWO). Financial support from the University Bordeaux 1, the CNRS and the Région Aquitaine is gratefully acknowledged. The authors thank Prof. Jan Reedijk and Dr. Stefania Tanase for stimulating discussions.

Supporting Information Available: Figures S1 and S2 showing ac magnetic properties of complex $\mathbf{4}$ and further details in CIF format on the crystal structures of complexes $\mathbf{3}, \mathbf{4}$, and $\mathbf{5}$, including atomic coordinates, displacement parameters, bond lengths, and bond angles. This material is available free of charge via the Internet at http://pubs.acs.org.

IC0605322 